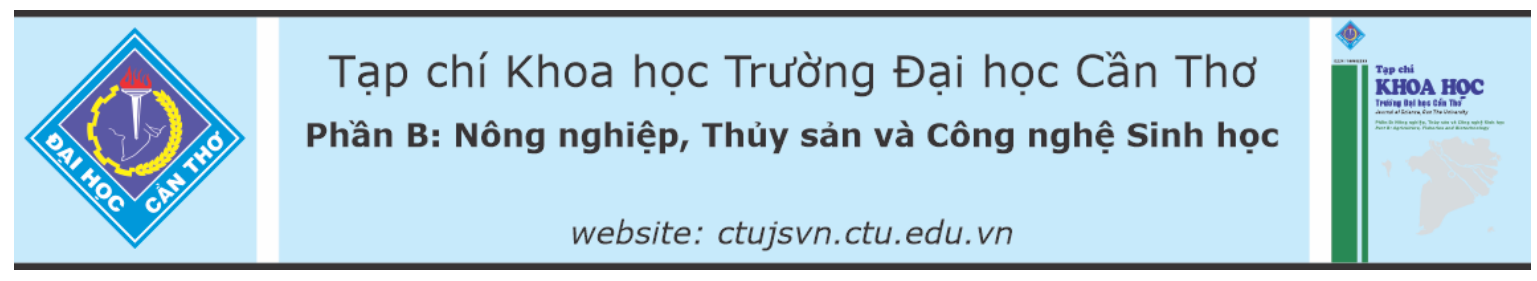

DOI: $10.22144 / c t u . j v n .2021 .190$

\title{
ĐặC ĐIỂM PHÂN BỐ CỦA LỚP CHÂN BỤNG (GASTROPODA) Ở KHU VỰC NUÔI TRỒNG THỦY SẢN TRÊN TUYẾN SÔNG HậU
}

\author{
Âu Văn Hóa ${ }^{*}$, Nguyễn Thị Kim Liên, Huỳnh Trường Giang và Vũ Ngọc Út \\ Khoa Thủy sản, Truoòng Đại học Cần Tho \\ *Nguoòi chịu trách nhiệm về bài viết: Âu Văn Hóa (email: avhoa@ctu.edu.vn)
}

\section{Thông tin chung:}

Ngày nhận bài: $26 / 02 / 2021$

Ngày nhận bài sủa: 18/09/2021

Ngày duyệt đăng: 25/12/2021

\section{Title:}

Distribution characteristics of Gastropods in the aquaculture areas along Hau river

\section{Tù̀ khóa:}

Gastropoda, mật độ, sông Hậu, thành phần loài

\section{Keywords:}

Density, Gastropoda, Hau river, species composition

\begin{abstract}
The study is to determine the distribution of Gastropods in the aquaculture areas along Hau river at An Giang and Can Tho province to serve as a basis for quality assessment of the water sources. The study was conducted by sampling benthos at 19 sites on the main river and tributaries in March, June, September and December, 2019. The results showed a total of 24 species of Gastropods belonging to 17 genera, 11 families and 7 orders. The number of species recorded in An Giang (19 species) was lower than that in Can Tho (21 species). The number of species obtained in the main river was 22 and in the tributaries was 19 species. The number of individuals fluctuated significantly from 0 to 5,447 inds $/ \mathrm{m}^{2}$ and no individual was found at AG4 site during June. The density of Gastropoda on the main river and tributaries ranged from 42 to 1,341 inds $/ \mathrm{m}^{2}$. The species composition and density of Gastropoda are very widely distributed and there are differences between the points, according to each the collection and on the main river and tributary in the study area. The Shannon diversity index $\left(H^{\prime}\right)$, species richness (d) and evenness index $\left(J^{\prime}\right)$ recorded on Hau river ranged from 0.9-2.0; 0.7-3.5 and 0.4-0.9, respectively. The results of H's index implied that sampling sites were in moderate to high level of pollution. The findings also provided a database to develop a biological monitoring program in the aquaculture area along the Hau river.
\end{abstract}

\section{TÓM TẮT}

Nghiên cưu được thực hiện nhằm xác định sự xuất hiện lớp Gastropoda ở khu vưc nuôi trồng thủy sản trên tuyến sông Hậu thuộc tỉnh An Giang và Cần Tho làm cơ sở đánh giá chất lương nguồn nước. Nghiên cứu được thưc hiện qua việc thu mẫu động vật đáy tại 19 điểm trên sông chính và sông nhánh vào thời điểm tháng 3, tháng 6, tháng 9 và tháng 12 năm 2019. Kết quả ghi nhận được 24 loài lớp chân bung thuộc 17 giống, 11 ho và 7 bộ. Số luợng loài ở An Giang (19 loài) thấp hơn Cần Tho (21 loài). Số loài thu được trên sông chính là 22 loài và sông nhánh là 19 loài. Mật độ Gastropoda dao động tù 0 đến 5.447 cá thể/ $m^{2}$ và không tìm thấy cá thể nào ở điểm $A G 4$ vào đơt 2; số cá thể trên sông chính và sông nhánh biến động tì̀ 42-1.341 cá thể/ $\mathrm{m}^{2}$. Thành phần loài và mật độ lớp Gastropoda phân bố rẩt rộng và có sụ khác biệt giữa các điểm thu, theo tù̀ng đợt và kể cả trên sông chính và sông nhánh tại khu vục nghiên cứu. Chỉ số đa dạng Shannon ( $\left.H^{\prime}\right)$, độ giàu loài $(d)$ và chi số đồng đều $\left(J^{\prime}\right)$ trên tuyến sông Hậu dao động lần luợt là 0,9-2,0, 0,7-3,5 và 0,4-0,9. Chỉ số H' cho thấy các vị trí thu mẫu ở mức ô nhiễm trung bình đến ô nhiễm nặng. Kết quả nghiên cứu còn là nguồn dĩ liệu co bản để xây dụng chuoong trình quan trắc sinh học trong khu vực nuôi trồng thủy sản trên sông Hậu. 


\section{1. ĐẶT VẤN ĐỀ}

Hiện nay, ngành nuôi thủy sản nước ngọt được thâm canh hóa ở khu vực Đồng bằng sông Cửu Long (ĐBSCL) nói chung, thành phố Cần Thơ và tỉnh $\mathrm{An}$ Giang nói riêng, trong đó đối tượng được chọn nuôi với quy mô lớn và thâm canh là cá tra. Chính vì vậy, nguồn nước bị ảnh hưởng bởi lượng chất thải được sinh ra từ việc nuôi cá tra là rất lớn. Trong mỗi vụ nuôi cá tra, lượng nước và bùn tích tụ ở đáy ao khá lớn và hầu như không được xử lí mà được thải trực tiếp ra môi trường nước làm ô nhiễm quanh khu vực nuôi cá. Mặt khác, việc sử dụng quá mức các loại thuốc và hóa chất trong thủy sản đã tác động xấu đến môi trường sống và sự phân bố các nhóm sinh vật trong thủy vực, trong đó có nhóm động vật đáy. Đặc biệt là lớp chân bụng (Gastropoda) mà đa phần các loài được khai thác làm thức ăn cho con người (Köhler et al., 2012) gồm Tarebia granifera, Gyraulus chinensis, Angulyagra polyzonata, Melanoides tuberculata, Pila ampullacea và làm thức ăn cho đối tượng thủy sản (Cortés et al., 2010). Ngoài ra, một số loài có khả năng gây hại nghiêm trọng trong nông nghiệp, gây thiệt hại cho ruộng lúa (Joshi et al., 2001; Greene, 2008). Khu hệ lớp Gastropoda nước ngọt ở châu Á khá đa dạng và đặc biệt là các sông lớn như sông Mê Kông có mức độ đa dạng rất cao (Attwood, 2009; Davis, 1979; Köhler et al., 2012; Strong et al., 2008). Các mối đe dọa đối với sự đa dạng sinh học của lớp Gastropoda có thể bao gồm các biện pháp kiểm soát và hạn chế sự phát triển quần thể của chúng trong thủy vực; các công trình xây dựng đập thủy điện dọc theo các con sông lớn, ô nhiễm, bồi lắng và các loài xâm hại, đặc biệt là Pomacea channeliculata (Köhler et al., 2012). Tuy nhiên, Việt Nam cũng như ở ĐBSCL có sự phân bố của loài ốc bươu vàng (Pomacea canaliculata), nó là một trong những loài ngoại lai đe dọa nghiêm trọng đển tính đa dạng sinh học, sản xuất nông nghiệp trong nước và nhiều nước vùng nhiệt đới, cận nhiệt đới và ôn đới trên thế giới (Halwart, 1994). Chính vì thế, nghiên cứu về sự xuất hiện của lớp Gastropoda ở khu vực nuôi trồng thủy sản trên tuyến sông Hậu là cần thiết nhằm đánh giá sự thích nghi của từng loài Gastropoda tại mỗi vị trí thu mẫu và tính đa dạng của chúng với mô hình nuôi bán thâm canh, thâm canh và nuôi lồng bè ở khu vực nuôi trồng thủy sản thuộc tỉnh An Giang và Cần Thơ, phục vụ cho quan trắc sinh học chất lượng nước trên địa bàn.

\section{PHƯƠNG PHÁP NGHIÊN CÚU}

Nghiên cứu được thực hiện ở khu vực nuôi trồng thủy sản nước ngọt thuộc tỉnh An Giang và Cần Thơ với 4 đợt thu mẫu ở các thời điểm là tháng 3 , tháng 6, tháng 9 và tháng 12 năm 2019 tại 19 điểm trên hệ thống sông chính, sông nhánh thuộc sông Hậu. Các vị trí thu mẫu ở khu vực nuôi trồng thủy sản trọng điểm với các hình thức như nuôi cá trong ao đất bán thâm canh, thâm canh và lồng bè. Chi tiết về các điểm thu được trình bày ở Bảng 1 và Hình 1 .

Bảng 1. Vị trí thu mẫu trên tuyến sông Hậu thuộc tỉnh An Giang và Cần Thơ

\begin{tabular}{|c|c|c|c|c|c|c|}
\hline \multirow{2}{*}{ STT } & \multirow{2}{*}{ Tỉnh } & \multirow{2}{*}{ Điểm thu } & \multirow{2}{*}{ Kí hiệu } & \multirow{2}{*}{ Địa điểm } & \multicolumn{2}{|r|}{ Vị trí } \\
\hline & & & & & Vĩ độ Bắc (N) & Kinh độ Đông (E) \\
\hline 1 & \multirow{10}{*}{ An Giang } & Vĩnh Ngưon & AG1 & S. nhánh & $10^{\circ} 44^{\prime} 06.18^{\prime \prime}$ & $105^{\circ} 06^{\prime} 19.98^{\prime \prime}$ \\
\hline 2 & & Cồn Khánh Hòa & $\mathrm{AG} 2$ & S. chính & $10^{\circ} 41^{\prime} 24.36^{\prime \prime}$ & $105^{\circ} 11^{\prime} 42.24^{\prime \prime}$ \\
\hline 3 & & Cầu Vịnh Tre & AG3 & S. nhánh & $10^{\circ} 37^{\prime} 07.02^{\prime \prime}$ & $105^{\circ} 12^{\prime} 34.44^{\prime \prime}$ \\
\hline 4 & & Cầu chữ $\mathrm{S}$ & AG4 & S. nhánh & $10^{\circ} 34^{\prime} 52.50^{\prime \prime}$ & $105^{\circ} 13^{\prime} 46.08^{\prime \prime}$ \\
\hline 5 & & Bến phà Rạch Gộc & AG5 & S. chính & $10^{\circ} 28^{\prime} 42.36^{\prime \prime}$ & $105^{\circ} 20^{\prime} 21.48^{\prime \prime}$ \\
\hline 6 & & Bến phà Sơn Đốt & AG6 & S. chính & $10^{\circ} 26^{\prime} 45.06^{\prime \prime}$ & $105^{\circ} 23^{\prime} 24.48^{\prime \prime}$ \\
\hline 7 & & Kinh Ông Cò & AG7 & S. nhánh & $10^{\circ} 19^{\prime} 26.28^{\prime \prime}$ & $105^{\circ} 19^{\prime} 48.66^{\prime \prime}$ \\
\hline 8 & & Kinh Tây An & AG8 & S. nhánh & $10^{\circ} 20^{\prime} 30.12^{\prime \prime}$ & $105^{\circ} 26^{\prime} 57.36^{\prime \prime}$ \\
\hline 9 & & Kinh Cái sao 2 & AG9 & S. nhánh & $10^{\circ} 18^{\prime} 34.02^{\prime \prime}$ & $105^{\circ} 26^{\prime} 07.32^{\prime \prime}$ \\
\hline 10 & & Kinh Cái sao 1 & AG10 & S. nhánh & $10^{\circ} 19^{\prime} 58.14^{\prime \prime}$ & $105^{\circ} 27^{\prime} 38.64^{\prime \prime}$ \\
\hline 11 & \multirow{9}{*}{ Cần Thơ } & Thạnh Mỹ & CT1 & S. nhánh & $10^{\circ} 14^{\prime} 16.56^{\prime \prime}$ & $105^{\circ} 24^{\prime} 09.84^{\prime \prime}$ \\
\hline 12 & & Sông Cái sắn & CT2 & S. nhánh & $10^{\circ} 17^{\prime} 42.10^{\prime \prime}$ & $105^{\circ} 31^{\prime} 09.70^{\prime \prime}$ \\
\hline 13 & & Bến phà Bò Ót & CT3 & S. chính & $10^{\circ} 17^{\prime} 14.60^{\prime \prime}$ & $105^{\circ} 27^{\prime} 04.20^{\prime \prime}$ \\
\hline 14 & & Bến phà Trà Uối & CT4 & S. chính & $10^{\circ} 17^{\prime} 12.06^{\prime \prime}$ & $105^{\circ} 31^{\prime} 19.32^{\prime \prime}$ \\
\hline 15 & & Thuận Hưng & CT5 & S. chính & $10^{\circ} 13^{\prime} 17.40^{\prime \prime}$ & $105^{\circ} 35^{\prime} 09.30^{\prime \prime}$ \\
\hline 16 & & Thới An & CT6 & S. chính & $10^{\circ} 08^{\prime} 57.84^{\prime \prime}$ & $105^{\circ} 39^{\prime} 14.16^{\prime \prime}$ \\
\hline 17 & & Cồn Khương & CT7 & S. chính & $10^{\circ} 04^{\prime} 02.64^{\prime \prime}$ & $105^{\circ} 46^{\prime} 40.26^{\prime \prime}$ \\
\hline 18 & & Cái Cui & CT8 & S. chính & $09^{\circ} 59^{\prime} 33.84^{\prime \prime}$ & $105^{\circ} 49^{\prime} 34.74^{\prime \prime}$ \\
\hline 19 & & Cái Côn & CT9 & S. chính & $09^{\circ} 55^{\prime} 39.18^{\prime \prime}$ & $105^{\circ} 53^{\prime} 59.40^{\prime \prime}$ \\
\hline
\end{tabular}


Mẫu được thu bằng gàu Petersen có diện tích miệng gàu $0,03 \mathrm{~m}^{2}$. Tại mỗi vị trí, thu tổng cộng 10 gàu theo mặt cắt ngang của dòng sông và cách bờ sông từ 5 đến $10 \mathrm{~m}$. Mẫu được cho vào sàng đáy với kích thước mắt lưới $0,5 \mathrm{~mm}$ để loại bỏ tạp chất (bùn và rác), rửa sạch, sau đó cố định bằng formalin với nồng độ từ 8 đến $10 \%$ rồi chuyển về phòng thí nghiệm, Khoa Thủy sản, Trường Đại học Cần Thơ để tiến hành phân tích. Thành phần loài Gastropoda được định danh đến loài bằng cách dựa vào các tài liệu phân loại theo Bouchard (2012), Đặng Ngọc Thanh và ctv. (1980), Madsen and Hung (2014), Nattarin et al. (2014), Sangpradub and Boosoong (2006) và Yunfang (1995).

Số lượng cá thể từng loài Gastropoda được đếm và xác định mật độ theo công thức: $\mathrm{D}\left(\right.$ cá thể $\left./ \mathrm{m}^{2}\right)=$ $\mathrm{X} / \mathrm{S}$. Trong đó, $\mathrm{X}$ là số lượng cá thể, $\mathrm{S}$ là diện tích thu mẫu $(\mathrm{S}=\mathrm{n} \mathrm{x} d ; \mathrm{n}$ là số lượng gàu thu và $\mathrm{d}$ là diện tích gàu đáy).
Đánh giá sự đa dạng và tính ưu thế thành phần loài Gastropoda theo địa điểm và theo đợt thu mẫu được tính dựa trên cơ sở mật độ trung bình của từng loài ở từng vị trí, từng đợt và phân tích bằng phần mềm PRIMER 6.1.5 (Plymouth Routines in Multivariate Ecological Research), Clarke and Gorley (2006) dựa vào các chỉ số sau:

- Chỉ số đa dạng của động vật đáy ShannonWeaver (H') (1963) được xác định theo công thức: $\mathrm{H}^{\prime}=-\Sigma$ pi.lnpi với $\mathrm{pi}=$ ni/N . Trong đó, ni là số lượng cá thể của loài thứ $\mathrm{i}$ và $\mathrm{N}$ là tổng số cá thể của Gastropoda trong mẫu.

- Chỉ số Margalef $(\mathrm{d}): \mathrm{d}=(\mathrm{S}-1) /(\ln \mathrm{N})$, trong đó $\mathrm{S}$ là tổng số loài, $\mathrm{N}$ là tổng số cá thể.

- Chỉ số đồng đều Pielou's $\left(\mathrm{J}^{\prime}\right)$ : $\mathrm{J}^{\prime}=\mathrm{H}^{\prime} / \mathrm{lnS}$, trong đó $\mathrm{S}$ là tổng số loài, $\mathrm{H}^{\prime}$ là chỉ số ShannonWeaver.

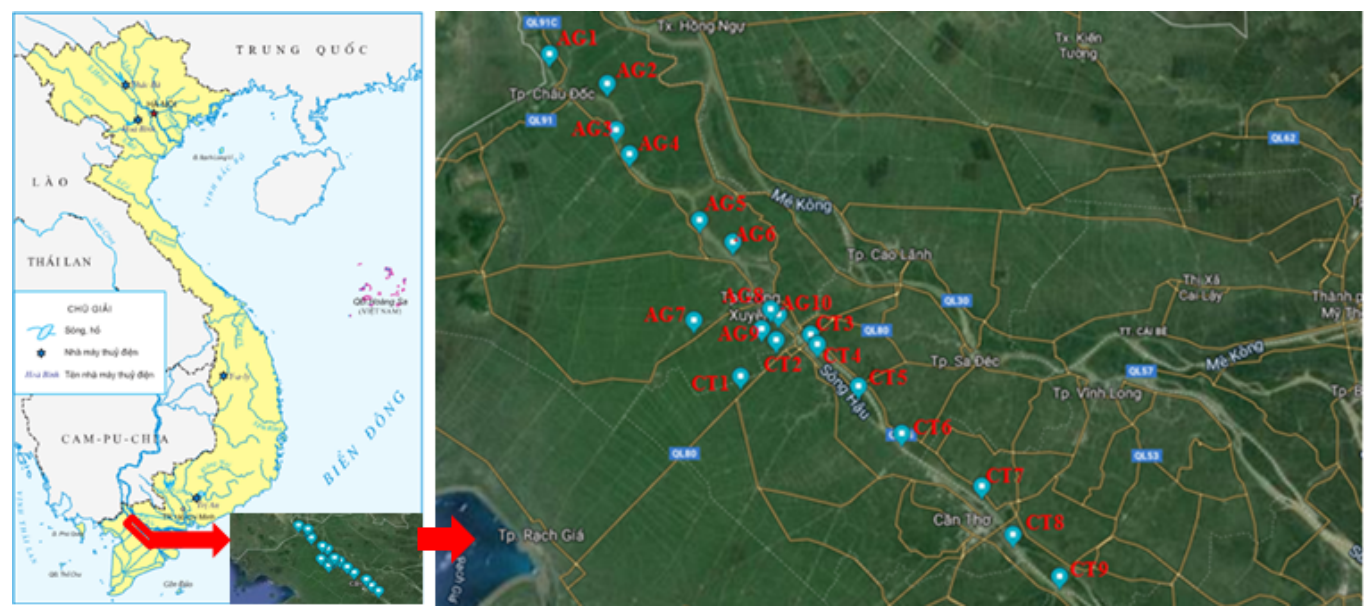

Hình 1. Vị trí thu mẫu trên sông Hậu

\section{KẾT QUẢ VÀ THẢO LUẬN}

\subsection{Sự phân bố lớp Gastropoda trong khu vực nuôi trồng thủy sản trên tuyến sông Hậu}

\subsubsection{Thành phần loài và mật độ lớp Gastropoda theo địa điểm nghiên cứu}

Số loài lớp chân bụng (Gastropoda) theo địa điểm ở khu vực nuôi trồng thủy sản trên tuyến sông Hậu (An Giang và Cần Thơ) ghi nhận tổng cộng là 24 loài thuộc 17 giống, 11 họ và 7 bộ. Nguyễn Thị Kim Liên và ctv. (2014) khảo sát thành phần loài động vật đáy trên sông Hậu giai đoạn mùa mưa tìm được 26 loài thuộc lớp Gastropoda. Kết quả nghiên cứu của Hoàng Đình Trung (2015) về thành phần loài động vật đáy ở sông Truồi, huyện Phú Lộc, tỉnh
Thừa Thiên Huế ghi nhận được 9 loài thuộc 8 giống, 4 họ, 2 bộ. Số loài Gastropoda ở sông Bồ của tỉnh Thừa Thiên Huế phát hiện được 30 loài thuộc 23 giống, 13 họ và 5 bộ (Hoàng Đình Trung và Vũ Thị Phương Anh, 2017). Kết quả nghiên cứu này thấp hơn so với 2 nghiên cứu của Nguyễn Thị Kim Liên và ctv. (2014) và Hoàng Đình Trung và Vũ Thị Phương Anh (2017), ngược lại cao hơn so với nghiên cứu Hoàng Đình Trung (2015). Sự khác biệt thành phần loài Gastropoda giữa các nghiên cứu có thể là do khảo sát ở khu vực khác nhau, số lượng điểm thu, thời gian và vị trí thu mẫu của mỗi nghiên cứu. Số loài Gastropoda thu được ở An Giang (19 loài) thấp hơn ở Cần Thơ (21 loài). Thành phần loài Gastropoda tại 19 điểm thu dao động từ 4 đến 13 loài, cao nhất tại điểm $\mathrm{AG} 9$ và $\mathrm{CT} 3$; thấp nhất tại 
điểm CT9. Ở sông chính, số loài Gastropoda tìm thấy từ 4 đến 13 loài, trung bình $8 \pm 3$ loài trong khi ở sông nhánh tìm được từ 5 đến 13 loài và trung bình $9 \pm 3$ loài (Hình 2). Một số loài Gastropoda xuất hiện tại các điểm thu trên tuyến sông Hậu cũng có sự khác biệt lớn, cụ thể loài Clea helena được phát hiện ở 19 điểm thu; trong khi các loài khác xuất hiện từ 2 đến 18 điểm thu. Tuy nhiên, 5 loài chỉ tìm được tại 1 điểm thu duy nhất như loài Balcis frielei (AG4), loài Gyraulus convexiusculus (AG9), loài Margarya sp. và loài Melanoides torolusa $(\mathrm{CT} 3)$ và loài Lymnaea auricularia (ốc (CT8) trong thời gian của nghiên cứu này.

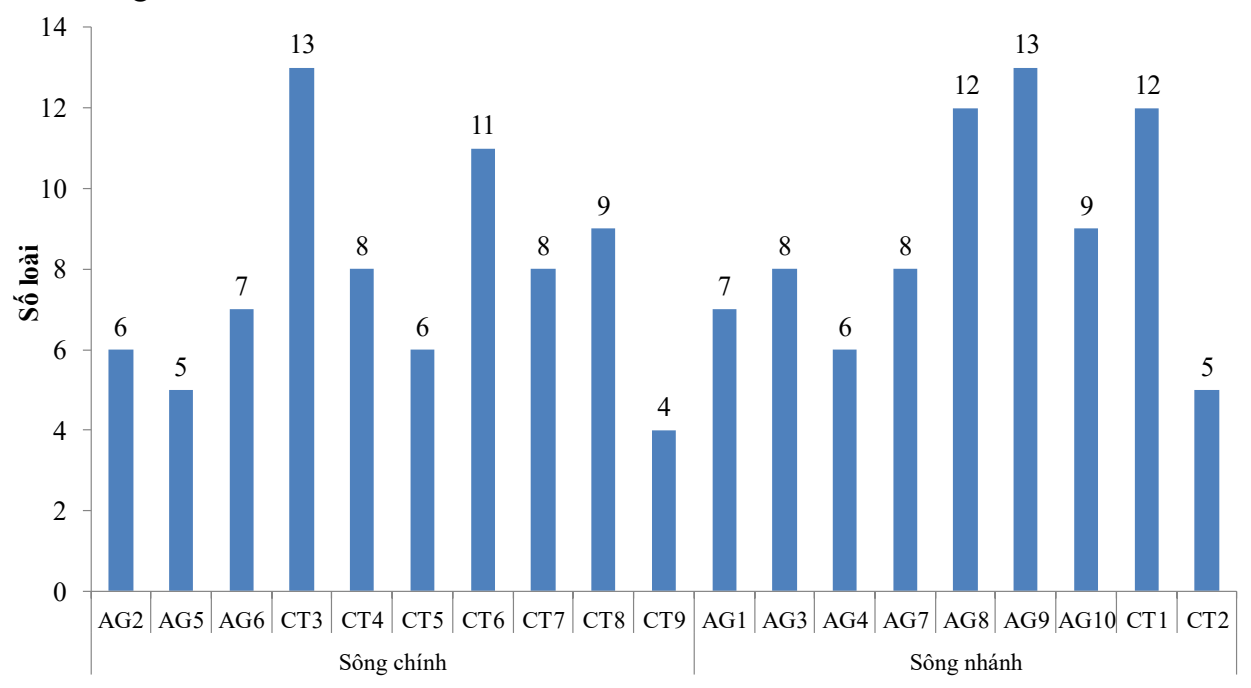

Hình 2. Số loài lớp Gastropoda tại các địa điểm nghiên cứu

Mật độ trung bình Gastropoda tại các địa điểm ở khu vực nghiên cứu trên tuyến sông Hậu qua 4 tháng thu mẫu dao động từ 110 đến 717 cá thể $/ \mathrm{m}^{2}$ trung bình $343 \pm 264$ cá thể $/ \mathrm{m}^{2}$, cao nhất ở tháng 6 và thấp nhất ở tháng 9 . Tương tự, mật độ Gastropoda theo từng điểm thu dao động từ 0 đến 5.447 cá thể $/ \mathrm{m}^{2}$, cao nhất ở điểm CT1 vào tháng 9 và không tìm thấy cá thể nào ở điểm $\mathrm{AG} 4$ vào tháng 6 và cả hai vị trí này đều tập trung vào sông nhánh. Ở sông chính, mật độ Gastropoda tại các vị trí thu mẫu dao động từ 7 đển 433 cá thể $/ \mathrm{m}^{2}$ trung bình $101 \pm 104$ cá thể $/ \mathrm{m}^{2}$ thấp hơn so với sông nhánh và đạt giá trị là $630 \pm 1.276$ cá thể $/ \mathrm{m}^{2}$ (Bảng 2). Tuy nhiên, mật độ một số loài Gastropoda đạt giá trị cao ở các vị trí thu mẫu bao gồm vào tháng 3 với 2 loài Sermyla riqueti và loài Melanoides tuberculata ghi nhận lần lượt 2.837 cá thể/ $\mathrm{m}^{2}$ tại điểm $\mathrm{AG} 9$ và 1.213 cá thể $/ \mathrm{m}^{2}$ tại điểm AG8; vào tháng 6 loài Tarebia granifera (5.297 cá thể $\left./ \mathrm{m}^{2}\right)$ tại điểm CT1, loài Melanoides tuberculata $\left(3.287\right.$ cá thể/ $\left.\mathrm{m}^{2}\right)$ và loài Filopaludina martensi (1.280 cá thể/ $\left.\mathrm{m}^{2}\right)$ tại điểm AG9; loài Thiara australis (1.147 cá thể/ $\left.\mathrm{m}^{2}\right)$ tại điểm $\mathrm{CT} 1$ vào tháng 12. Nhìn chung, mật độ Gastropoda theo từng vị trí thu mẫu, theo tháng, ở sông chính và sông nhánh biến động liên tục do ảnh hưởng các yếu tố thủy lý và thủy hóa của môi trường nước trong thủy vực tự nhiên bởi những hoạt động nuôi trồng thủy sản, nước thải sinh hoạt, sản xuất nông nghiệp và các khu công nghiệp. Theo Voshell (2002), các yếu tố thủy lý quan trọng ảnh hưởng đến sự phân bố của động vật đáy (trong đó có lớp Gastropoda) như nhiệt độ nước, thể tích nước, lưu tốc dòng chảy, tính chất nền đáy và mối quan hệ năng lượng. Theo nhận định của Strzelec and Królczyk (2004), nhiều loài thuộc Gastropoda chịu đựng được hầu hết các biến động của các yếu tố lý hóa học và sự hiện diện của chúng bị ảnh hưởng bởi chất lượng nền đáy và sự phong phú của cây cỏ thủy sinh, ở các dòng sông nền đáy phù hợp nhất cho Gastropoda phát triển là nền đáy cát trên bề mặt có phủ một lớp mỏng vật chất hữu cơ mịn. 
Bảng 2. Mật độ lớp chân bụng (Gastropoda) tại khu vực nghiên cứu

\begin{tabular}{cllrrrr}
\hline \multirow{2}{*}{ STT } & \multirow{2}{*}{ Ký hiệu } & \multirow{2}{*}{ Địa điểm } & Tháng 3 & Mật độ (cá thể/ $\mathbf{2}$ ' & Tháng 9 & Tháng 12 \\
\cline { 4 - 7 } & AG1 & S. nhánh & 140 & 23 & 23 & 97 \\
2 & AG2 & S. chính & 23 & 80 & 13 & 100 \\
3 & AG3 & S. nhánh & 23 & 57 & 90 & 20 \\
4 & AG4 & S. nhánh & 53 & - & 30 & 3 \\
5 & AG5 & S. chính & 27 & 213 & 23 & 37 \\
6 & AG6 & S. chính & 23 & 433 & 110 & 313 \\
7 & AG7 & S. nhánh & 77 & 290 & 53 & 250 \\
8 & AG8 & S. nhánh & 1.660 & 860 & 497 & 690 \\
9 & AG9 & S. nhánh & 3.020 & 4.827 & 747 & 237 \\
10 & AG10 & S. nhánh & 13 & 193 & 57 & 90 \\
11 & CT1 & S. nhánh & 277 & 5.447 & 133 & 1.350 \\
12 & CT2 & S. nhánh & 50 & 373 & 43 & 273 \\
13 & CT3 & S. chính & 63 & 83 & 67 & 230 \\
14 & CT4 & S. chính & 73 & 150 & 37 & 173 \\
15 & CT5 & S. chính & 293 & 257 & 60 & 43 \\
16 & CT6 & S. chính & 7 & 40 & 27 & 57 \\
17 & CT7 & S. chính & 37 & 40 & 33 & 113 \\
18 & CT8 & S. chính & 270 & 257 & 20 & 130 \\
19 & CT9 & S. chính & 7 & 7 & 27 & 23 \\
\hline & Trung bình & & $323 \pm 752$ & $717 \pm 1.574$ & $110 \pm 188$ & $223 \pm 316$ \\
\hline
\end{tabular}

3.1.2. Số loài và mật độ lóp Gastropoda theo tháng ở sông chính và sông nhánh

Số loài Gastropoda trên sông chính và sông nhánh thuộc tuyến sông Hậu qua 4 tháng thu mẫu dao động từ 6 đến 16 loài, cao nhất vào tháng 9 và thấp nhất ở tháng 6 thuộc sông nhánh. Số loài Gastropoda trên sông chính (22 loài) cao hơn sông nhánh (19 loài). Thành phần loài Gastropoda ghi nhận trên sông chính và sông nhánh có sự khác biệt lớn giữa các tháng thu mẫu trong thời gian nghiên cứu (Hình 3). Theo Nguyễn Thị Kim Liên và ctv. (2014), khảo sát thành phần loài động vật đáy trên sông Hậu giai đoạn mùa mưa ghi nhận lớp Gastropoda trên sông chính dao động từ 6 đến 10 loài, sông nhánh từ 0 đến 11 loài và thấp hơn so với nghiên cứu này. Mặt khác, 4 loài Margarya sp., loài Dostia violacea, loài Brotia swinhoei và loài Lymnaea auricularia xuất hiện chủ yếu trên sông chính, ngược lại sự xuất hiện ở sông nhánh có 2 loài Balcis frielei và loài Gyraulus convexiusculus. Kết quả này cho thấy quần thể động vật đáy, trong đó có lớp Gastropoda cũng chịu ảnh hưởng bởi chất lượng nước (Latha và Thanga, 2010); hàm lượng vật chất hữu cơ, tính chất nền đáy của thủy vực, sự phong phú của cây cỏ thủy sinh cũng như hàm lượng calcium (Qadri \& Yousuf, 2004). Kết quả nghiên cứu cho thấy, thành phần loài Gastropoda có sự phân bố trên sông chính và sông nhánh khác biệt ở khu vực nuôi trồng thủy sản với các hình thức nuôi bán thâm canh, thâm canh và nuôi lồng bè; chủ yếu là cá tra và các đối tượng khác như cá hú, cá lóc bông, cá trê, cá rô, cá điêu hồng, cá he vàng,... Các hoạt động nuôi trồng thủy sản như xả thải, nguồn thức ăn dư thừa, tính chất nền đáy, hàm lượng oxy hòa tan, lưu tốc dòng chảy, hàm lượng vật chất hữu cơ trong môi trường nước ảnh hưởng rất lớn đến sự phát triển quần thể Gastropoda tại các vị trí thu mẫu. 


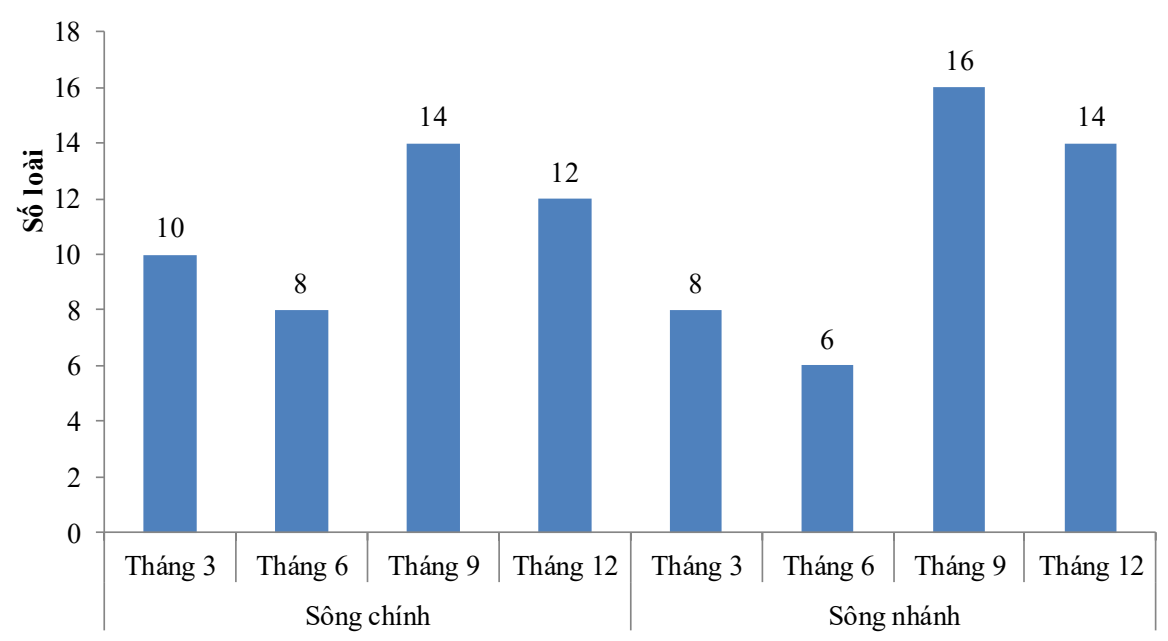

Hình 3. Số loài lớp Gastropoda theo tháng ở sông chính và sông nhánh

Mật độ Gastropoda theo sông chính và sông nhánh trên tuyến sông Hậu qua 4 tháng thu dao động từ 42 đến 1.341 cá thể/ $\mathrm{m}^{2}$ trung bình $357 \pm 435$ cá thể/ $\mathrm{m}^{2}$, cao nhất ở tháng 6 thuộc sông nhánh và thấp nhất ở tháng 9 thuộc sông chính. Ở sông chính, mật độ Gastropoda dao động từ 42 đến 156 cá thể $/ \mathrm{m}^{2}$, trung bình $101 \pm 49$ cá thể/ $\mathrm{m}^{2}$, thấp hơn 6 lần so với sông nhánh và đạt giá trị trung bình là $613 \pm 513$ cá thể/m² (Hình 4). Mặt khác, ở sông nhánh, một số loài được ghi nhận thuộc lớp Gastropoda có số lượng cá thể rất cao như với loài Sermyla riqueti là 315 cá thể/ $\mathrm{m}^{2}$ vào tháng 3 , loài Melanoides tuberculata $\left(434\right.$ cá thể/ $\left.\mathrm{m}^{2}\right)$ và Tarebia granifera (589 cá thể $/ \mathrm{m}^{2}$ ) ở tháng 6 , loài Thiara australis $(142$ cá thể/ $\mathrm{m}^{2}$ ) ở tháng 12 . Nguyễn Thị Kim Liên (2017) ghi nhận mật độ Gastropoda trên sông chính của sông Hậu từ 35 đến 176 cá thể $/ \mathrm{m}^{2}$ thấp hơn so với nghiên cứu này. Tóm lại, mật độ Gastropoda ở sông chính thấp hơn nhiều so với sông nhánh vào các thời điểm trong năm, có thể là do sông chính có tốc độ dòng chảy mạnh, mực nước cao và đặc tính dinh dưỡng thấp nên ảnh hưởng rất lớn đến sự phân bố của lớp Gastropoda là vì chúng có khả năng sống bám vào cây cỏ thủy sinh và nhóm sống đáy (vùi trong bùn); đây là các đặc tính giúp chúng phân bố và phát triển mạnh trong thủy vực tự nhiên. Dillon
(2000) cho rằng sự phân bố của Gastropoda trong môi trường nước ngọt phụ thuộc vào khả năng của chúng đối với môi trường nơi chúng sinh trưởng và tồn tại ở đó. Mặt khác, sự phân bố của nhóm động vật đáy chịu ảnh hưởng rất lớn của các hoạt động nuôi trồng thủy sản và sản xuất nông nghiệp, những hoạt động này đã làm thay đổi điều kiện môi trường nước nơi chúng sống (Dương Trí Dũng và ctv., 2007; Hellawell, 1986). Các vị trí thu mẫu chịu tác động mạnh từ hoạt động nuôi trồng thủy sản trong ao, lồng bè diễn ra liên tục; ngoài ra còn có các hoạt động sản xuất và sinh hoạt của con người. Nguồn nước thải từ các hoạt động này đã làm thay đổi các yếu tố môi trường như $\mathrm{pH}$, độ kiềm, hàm lượng đạm, lân, sự tích tụ vật chât hữu cơ, nguồn thức ăn dư thừa, làm ảnh hưởng sự phát triển quần thể nhóm Gastropoda sống đáy. Sự phóng thích trực tiếp một số lượng lớn nước thải giàu dinh dưỡng gồm các chất cặn lắng, thức ăn dư thừa và các sản phẩm của quá trình trao đổi chất vào trong nước và tích tụ dưới nền đáy (Temporetti et al., 2001); làm thay đổi mạnh mẽ chất lượng nước một cách trực tiếp hoặc gián tiếp, từ đó làm thay đổi cấu trúc quần thể động vật đáy cũng như quần thể nhóm Gastropoda (Pitta et al., 1999). 


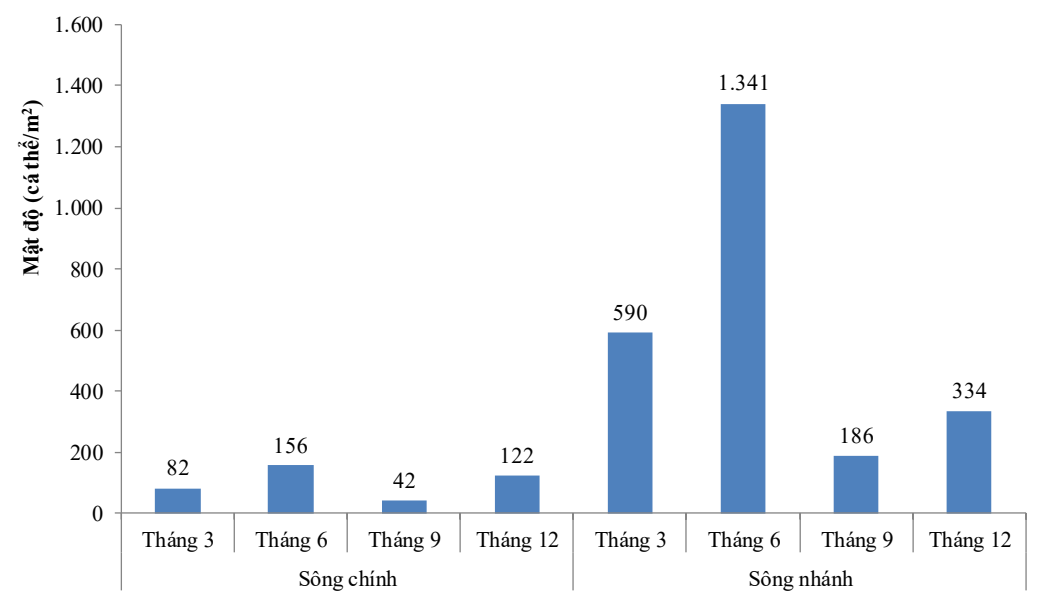

Hình 4. Mật độ lớp Gastropoda theo tháng ở sông chính và sông nhánh

3.2. Đa dạng sinh học lớp Gastropoda trên tuyến sông Hậu

\subsection{1. Đa dạng sinh hoc lóp Gastropoda theo địa điểm nghiên cứu}

Tính đa dạng thành phần loài Gastropoda giữa các điểm thu ở khu vực nuôi trồng thủy sản trên tuyến sông Hậu thuộc tỉnh An Giang ghi nhận tổng số loài dao động từ 5 đến 13 loài và tương ứng tổng số lượng cá thể là 22 đến 2.208 cá thể $/ \mathrm{m}^{2}$; độ giàu loài $(\mathrm{d})$ đạt giá trị từ 0,9 đến 1,8 . Độ đồng đều $\left(\mathrm{J}^{\prime}\right)$ ở các điểm thu từ 0,6 đến 0,9 . Về chỉ số đa dạng Shannon-Weaver $\left(\mathrm{H}^{\prime}\right)$ có sự chênh lệch giữa các điểm thu, dao động từ 1,1 đển 1,7 . Tích lũy loài ưu thế của quần xã Gastropoda tại các điểm thu mẫu AG1, AG2, AG5, AG6, AG7 và AG8 cho thấy mức độ ổn định quần xã Gastropoda khá thấp với 1 loài có mật độ chiếm từ 40 đến $60 \%$ tổng số mật độ, với sự ưu thế loài Melanoides tuberculata có mật độ 511 cá thể/ $\mathrm{m}^{2}(55,1 \%)$ và 2 loài Clea helena và Cipangopaludina lecythoides có mật độ chiếm $60 \%$. Ở điểm AG3, AG4, AG9 và AG10 tính ổn định quần xã Gastropoda tương đối với chỉ số ưu thế tích lũy loài đầu tiên $<40 \%$, với sự ưu thế của loài Melanoides tuberculata có mật độ 829 cá thể/ $\mathrm{m}^{2}$ (37,6\%) (Bảng 3 \& Hình 5).

Bảng 3. Đa dạng sinh học lớp Gastropoda theo địa điểm nghiên cứu

\begin{tabular}{|c|c|c|c|c|c|c|}
\hline STT & Điểm thu & $\begin{array}{l}\text { Tổng số } \\
\text { loài (S) }\end{array}$ & $\begin{array}{r}\text { Số lượng cá thể } \\
(\mathbf{N})\left(\mathrm{ct} / \mathbf{m}^{2}\right)\end{array}$ & $\begin{array}{r}\text { Độ giàu loài } \\
\text { (d) }\end{array}$ & $\begin{array}{r}\text { Độ đồng đều } \\
\left(J^{\prime}\right)\end{array}$ & $\begin{array}{r}\text { Chỉ số } \\
\text { Shannon (H') }\end{array}$ \\
\hline 1 & AG1 & 7 & 71 & 1,4 & 0,6 & 1,1 \\
\hline 2 & AG2 & 6 & 54 & 1,3 & 0,7 & 1,2 \\
\hline 3 & AG3 & 8 & 48 & 1,8 & 0,8 & 1,7 \\
\hline 4 & AG4 & 6 & 22 & 1,6 & 0,9 & 1,5 \\
\hline 5 & AG5 & 5 & 75 & 0,9 & 0,7 & 1,1 \\
\hline 6 & AG6 & 7 & 220 & 1,1 & 0,6 & 1,2 \\
\hline 7 & AG7 & 8 & 168 & 1,4 & 0,8 & 1,6 \\
\hline 8 & AG8 & 12 & 927 & 1,6 & 0,6 & 1,4 \\
\hline 9 & AG9 & 13 & 2.208 & 1,6 & 0,6 & 1,5 \\
\hline 10 & AG10 & 9 & 88 & 1,8 & 0,8 & 1,7 \\
\hline 11 & CT1 & 13 & 1.802 & 1,6 & 0,4 & 0,9 \\
\hline 12 & CT2 & 5 & 185 & 0,8 & 0,9 & 1,5 \\
\hline 13 & CT3 & 13 & 111 & 2,5 & 0,8 & 1,9 \\
\hline 14 & CT4 & 8 & 108 & 1,5 & 0,7 & 1,4 \\
\hline 15 & CT5 & 6 & 163 & 1,0 & 0,8 & 1,5 \\
\hline 16 & CT6 & 11 & 33 & 2,9 & 0,8 & 1,9 \\
\hline 17 & CT7 & 8 & 56 & 1,7 & 0,8 & 1,8 \\
\hline 18 & CT8 & 9 & 169 & 1,6 & 0,7 & 1,5 \\
\hline 19 & СТ9 & 4 & 16 & 1,1 & 0,7 & 1,0 \\
\hline
\end{tabular}


Tương tự, đa dạng thành phần loài Gastropoda giữa các điểm thu trên tuyến sông Hậu ở Cần Thơ với tổng số loài dao động từ 4 đến 13 loài và tương ứng tổng số lượng cá thể là 16 đến 1.802 cá thể $/ \mathrm{m}^{2}$; độ giàu loài (d) đạt giá trị từ 0,8 đến 2,9 . Độ đồng đều $\left(\mathrm{J}^{\prime}\right)$ ở các điểm thu từ 0,4 đến 0,9 . Chỉ số đa dạng Shannon-Weaver (H') có sự chênh lệch giữa các điểm thu dao động từ 0,9 đến 1,9 . Tích lũy loài ưu thế quần xã Gastropoda tại điểm CT1 cho thấy mức

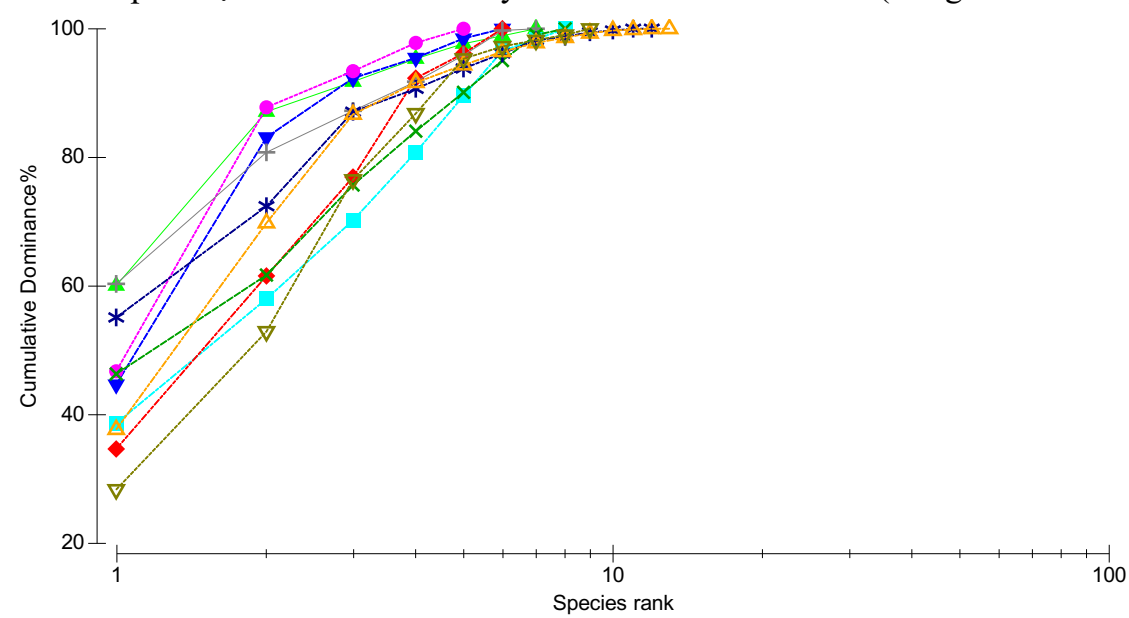

Hình 5. Tích lũy loài ưu thế ở khu vực thu mẫu trên sông Hậu thuộc tỉnh An Giang

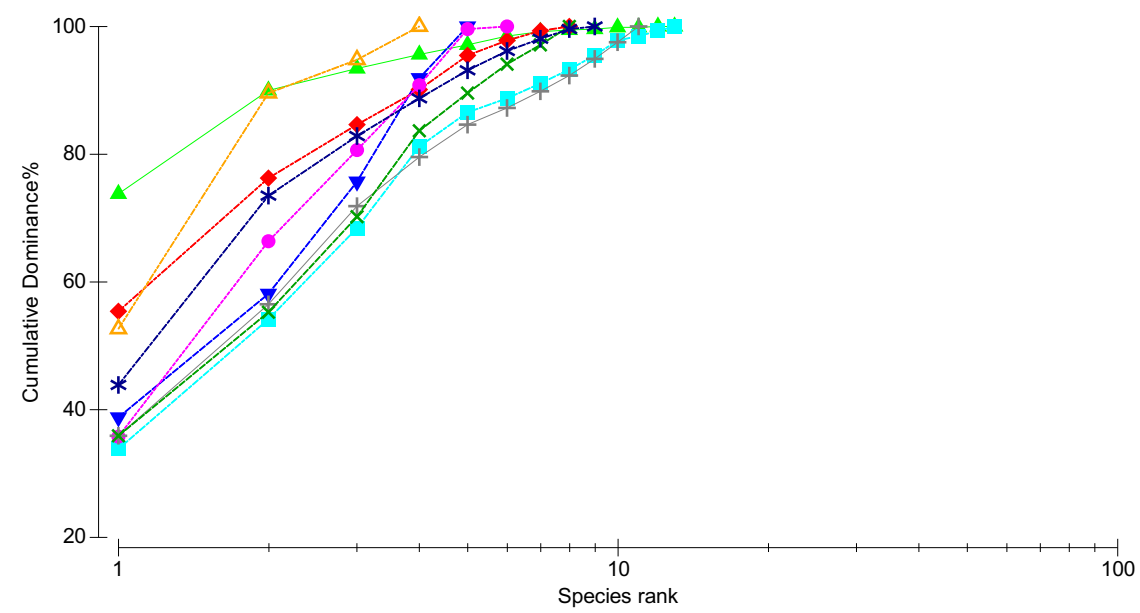

Hình 6. Tích lũy loài ưu thế ở khu vụ̣c thu mẫu trên sông Hậu thuộc tỉnh Cần Thơ

\subsection{2. Đa dang sinh hoc lóp Gastropoda theo sông chính và sông nhánh}

Tính đa dạng thành phần loài Gastropoda ở sông chính trên tuyến sông Hậu qua 4 tháng thu mẫu với tổng số loài từ 8 đến 14 loài tương ứng số cá thể là 82 đến 156 cá thể $/ \mathrm{m}^{2}$; độ giàu loài (d) đạt giá trị từ 1,4 đến 3,5 . Độ đồng đều $\left(\mathrm{J}^{\prime}\right)$ và chỉ số đa dạng độ ổn định quần xã Gastropoda rất thấp với 1 loài có mật độ chiếm lớn hơn $60 \%$ tổng số mật độ, với sự ưu thế loài Tarebia granifera có mật độ 1.329 cá thể/ $/ \mathrm{m}^{2}(73,8 \%)$. Ở các điểm CT4, CT8, và CT9 tính ổn định quần xã Gastropoda khá thấp với 1 loài có mật độ chiếm $40 \%$ đến $60 \%$ tổng số mật độ. Ở điểm $\mathrm{CT} 2, \mathrm{CT} 3, \mathrm{CT} 5, \mathrm{CT} 6$ và $\mathrm{CT} 7$, tính ổn định quần xã Gastropoda tương đối với chỉ số ưu thế tích lũy loài đầu tiên $<40 \%$ (Bảng $3 \&$ Hình 6 ).

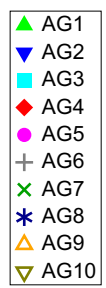

Shannon-Weaver ( $\left.\mathrm{H}^{\prime}\right)$ gần như tương đương nhau ở các tháng thu mẫu. Tích lũy loài ưu thế quần xã Gastropoda tại 4 tháng thu trên sông chính cho thấy mức độ ổn định quần xã Gastropoda thấp với 1 loài có mật độ chiếm < $40 \%$ tổng số mật độ, với sự ưu thế loài Cipangopaludina lecythoides có mật độ 13 cá thể/ $/ \mathrm{m}^{2}(32,0 \%)$ (Bảng 4 \& Hình 7). 
Bảng 4. Đa dạng sinh học lớp Gastropoda theo sông chính và sông nhánh

\begin{tabular}{|c|c|c|c|c|c|c|}
\hline $\begin{array}{c}\text { Đắc } \\
\text { điểm }\end{array}$ & Tháng thu & $\begin{array}{l}\text { Tổng số } \\
\text { loài (S) } \\
\end{array}$ & $\begin{array}{l}\text { Số lượng cá thể } \\
(\mathbf{N})\left(\mathbf{c t} / \mathbf{m}^{2}\right)\end{array}$ & $\begin{array}{l}\text { Độ giàu } \\
\text { loài }(\mathrm{d})\end{array}$ & $\begin{array}{l}\text { Độ đồng } \\
\text { đều (J') }\end{array}$ & $\begin{array}{c}\text { Chỉ số Shannon } \\
\left(\mathbf{H}^{\prime}\right)\end{array}$ \\
\hline \multirow{4}{*}{$\begin{array}{l}\text { Sông } \\
\text { chính }\end{array}$} & Tháng 3 & 12 & 82 & 2,5 & 0,8 & 1,9 \\
\hline & Tháng 6 & 8 & 156 & 1,4 & 0,9 & 1,8 \\
\hline & Tháng 9 & 14 & 42 & 3,5 & 0,8 & 2,0 \\
\hline & Tháng 12 & 12 & 122 & 2,3 & 0,8 & 1,9 \\
\hline \multirow{4}{*}{$\begin{array}{l}\text { Sông } \\
\text { nhánh }\end{array}$} & Tháng 3 & 9 & 590 & 1,3 & 0,6 & 1,3 \\
\hline & Tháng 6 & 6 & 1.341 & 0,7 & 0,8 & 1,3 \\
\hline & Tháng 9 & 16 & 186 & 2,9 & 0,7 & 2,0 \\
\hline & Tháng 12 & 14 & 334 & 2,2 & 0,7 & 1,8 \\
\hline
\end{tabular}

Tương tự, đa dạng thành phần loài Gastropoda ở sông nhánh trên tuyến sông Hậu qua 4 tháng thu mẫu có tổng số loài từ 6 đến 16 loài tương ứng với tổng số cá thể là 186 đến 1.341 cá thể/ $\mathrm{m}^{2}$; độ giàu loài $(\mathrm{d})$ đạt giá trị từ 0,7 đến 2,9 . Độ đồng đều $(\mathrm{J}$ ') qua 4 tháng thu mẫu từ 0,6 đến 0,8 . Chỉ số đa dạng Shannon-Weaver (H') trên sông nhánh chênh lệch tương đối lớn và thể hiện từ 1,3 đến 2,0 . Tích lũy loài ưu thế quần xã Gastropoda tại tháng 3 , tháng 6

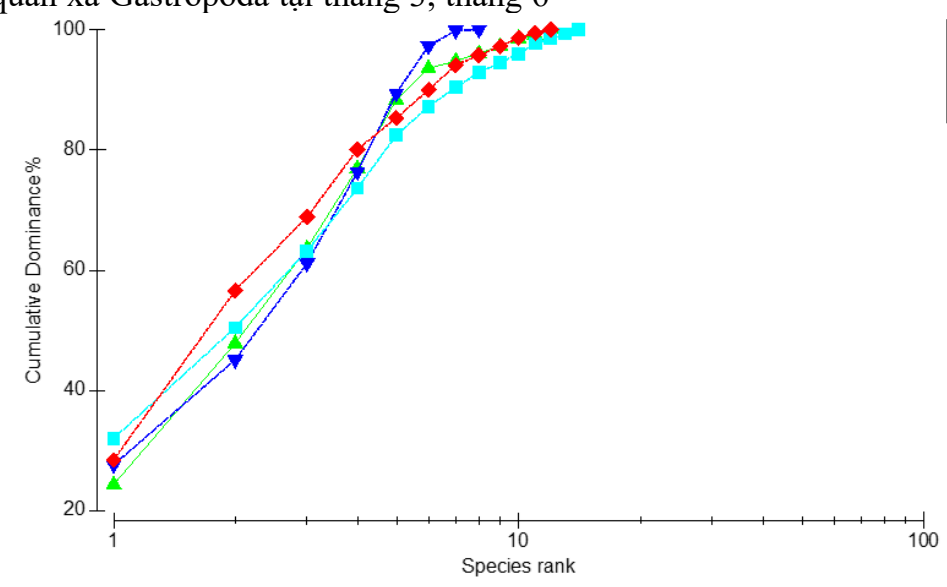

Hình 7. Tích lũy loài ưu thế ở khu vực thu mẫu trên sông chính

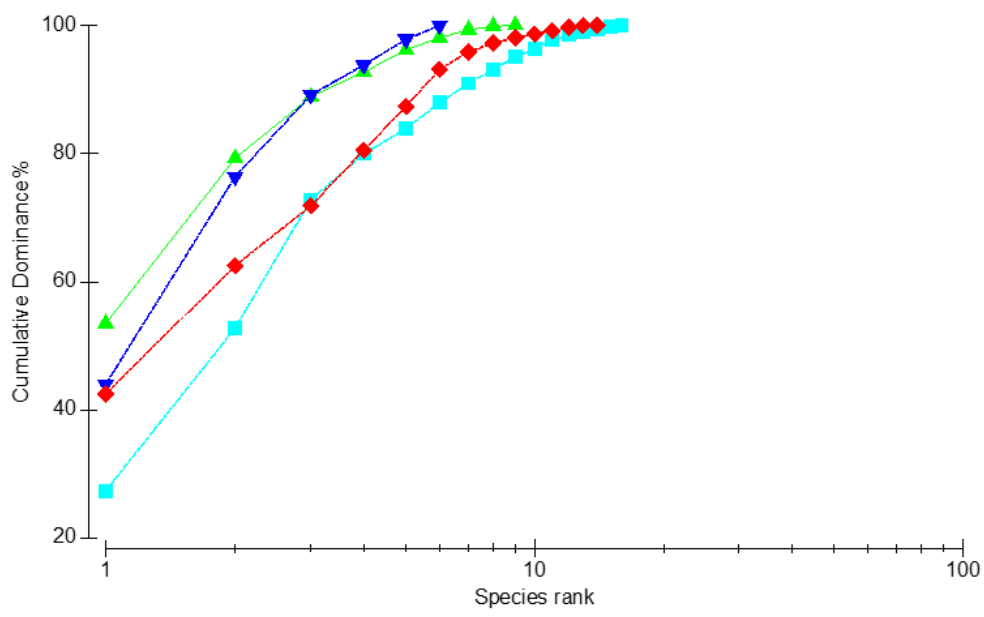

Hình 8. Tích lũy loài ưu thế ở khu vực thu mẫu trên sông nhánh và tháng 12 tính ổn định quần xã Gastropoda khá thấp với 1 loài có mật độ chiếm $40 \%$ đến $60 \%$ tổng số mật độ, với sự ưu thế loài Sermyla riqueti có mật độ 315 cá thể/ $\mathrm{m}^{2}$ (53,4\%), loài Thiara australis (142 cá thể/ $\left.\mathrm{m}^{2} ; 42,4 \%\right)$ và loài Tarebia granifera ( 589 cá thể $/ \mathrm{m}^{2} ; 43,9 \%$ ). Ở tháng 9 , tính ổn định quần xã Gastropoda tương đối với chỉ số ưu thế tích lũy loài đầu tiên 27,3\% tổng số mật độ (Bảng 4 \& Hình 8).
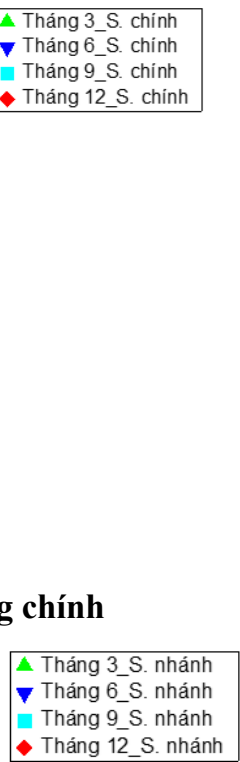

Tháng $9 \_S$. nhánh
Tháng $12 \mathrm{~S}$. nhánh 
Kết quả khảo sát cho thấy thành phần loài Gastropoda tại 19 điểm thu, sông chính và sông nhánh khá đa dạng. Theo kết quả nghiên cứu của Staub et al. (1970) về phân mức chất lượng nước vào chỉ số đa dạng Shannon ( $\left.\mathrm{H}^{\prime}\right)$, nghiên cứu này tại các điểm AG1, AG2, AG3, AG4, AG5, AG6, AG7, AG8, AG9, AG10, CT2, CT3, CT4, CT5, CT6, CT7, CT8 và 4 đợt thu mẫu ở sông chính, sông nhánh có mức ô nhiễm trung bình $\left(1<\mathrm{H}^{\prime} \leq 2\right)$; còn lại điểm $\mathrm{CT} 1$ và $\mathrm{CT}$ 9 ở mức rất ô nhiễm $\left(\mathrm{H}^{\prime} \leq 1\right)$ ngoài hoạt động nuôi trồng thủy sản, tại đây còn ảnh hưởng bởi nước thải do gần khu công nghiêp và khu dân cư. Theo Nguyễn Thị Kim Liên (2017), chỉ số H' trên sông chính và sông nhánh ghi nhận lần lượt là 0,39 đến 2,61 và 0,75 đến 2,60 và cao hơn so với nghiên cứu này. Điều này cho thấy tính đa dạng thành phần loài động vật đáy có sự thay đổi qua các thời điểm nghiên cứu và phụ thuộc vào các yếu tố chất lượng nước (Flores \& Zafaralla, 2012).

Tóm lại, thành phần loài và mật độ lớp Gastropoda được khảo sát qua 19 điểm trên sông Hậu cho thấy có sự khác biệt rất lớn giữa các điểm thu, theo đợt thu và kể cả trên sông chính và sông nhánh ở khu vực nuôi trồng thủy sản. Kết quả nghiên cứu cho thấy thành phần loài Gastropoda thích nghi rộng và chịu đựng được môi trường ô nhiễm trung bình đến ô nhiễm nặng. Sự phân bố của lớp Gastropoda ở sông chính thấp hơn nhiều so với sông nhánh cả về thành phần và mật độ tại thời điểm nghiên cứu.

\section{KẾT LUẬN}

Tổng cộng 24 loài thuộc 17 giống, 11 họ, 7 bộ ở khu vực nuôi trồng thủy sản trên tuyến sông Hậu. Số lượng loài tại các điểm ở An Giang thấp hơn Cần Thơ; và sông chính thấp hơn sông nhánh.

Mật độ lớp Gastropoda theo từng điểm dao động từ 0 đến 5.447 cá thể $/ \mathrm{m}^{2}$ và không bắt gặp cá thể nào ở điểm $\mathrm{AG} 4$ vào tháng 6 ; mật độ sông nhánh cao hơn 6 lần so với sông chính và dao động từ 42 đến 1.341 cá thể $/ \mathrm{m}^{2}$.

Số loài và mật độ lớp Gastropoda thích nghi rộng và có sự khác biệt giữa các điểm thu, theo từng tháng và kể cả trên sông chính và sông nhánh tại khu vực nghiên cứu. Chỉ số đa dạng Shannon $\left(\mathrm{H}^{\prime}\right)$, độ giàu loài $(\mathrm{d})$ và chỉ số đồng đều $(\mathrm{J}$ ') dao động lần lượt là 0,9 đến $2,0,0,7$ đến 3,5 và 0,4 đến 0,9 . Chỉ số $\mathrm{H}^{\prime}$ cho thấy các vị trí thu mẫu ở mức ô nhiê̂m trung bình đến ô nhiễm nặng. Một số loài phân bố và chiểm ưu thế tại vị trí thu mẫu như Clea helena, Melanoides tuberculata, Sermyla riqueti, Filopaludina martensi, Tarebia granifera và Thiara australis.

\section{LỜI CẢM TẠ}

Đề tài này được tài trợ bởi Dự án Nâng cấp Trường Đại học Cần Thơ VN14-P6 bằng nguồn vốn vay ODA từ Chính phủ Nhật Bản.

\section{TÀI LIỆU THAM KHẢO}

Attwood, S.W. (2009). Mekong Schistosomiasis: where did it come from and where is it going? In: Campbell, I.C. (Ed.), The Mekong: Biophysical Environment of an International River Basin. Elsevier, New York, NY, 273-295. https://doi.org/10.1016/B978-0-12-3740267.00011-5

Bouchard, R. W. (2012). Guide to Aquatic Invertebrate Families of Mongolia. Identification Mannual for Students. Citizens Monitors, and Aquatic Resource Professionals.

Clarke, K.R. \& Gorley, R.N. (2006). Plymouth Routines In Multivariate Ecological Research (PRIMER V.6) User Manual/Tutorial, Primer - E.

Cortés, D.A., Dolz, G., Zaniga, J.J.R., Rocha, A.E.J., \& Alán, D.L. (2010). Centrocestus formosanus (Opisthorchiida: Heterophyidae) as a cause of death in gray tilapia fry Oreochromis niloticus (Perciforme: Cichlidae) in the dry Pacific of Costa Rica. Rev. Biol. Trop, 58(4), 1453-1465. https://doi.org/10.15517/rbt.v58i4.5423

Đặng Ngọc Thanh, Trần Thái Bái \& Phạm Văn Miên (1980). Định loại động vật không xưong sống nuớc ngọt Miền Bắc Việt Nam. Nhà xuất bản Khoa học và Kỹ thuật, Hà Nội.

Davis, G.M. (1979). The origin and evolution of the gastropod family Pomatiopsidae, with emphasis on the Mekong River Triculinae. Acad. Nat. Sci. Phila. Monogr, 20, 1-120.

Dillon, R. T. Jr. (2000). The ecology of freshwater Molluscs. Cambridge University Press, Cambridge, U.K.. https://doi.org/10.1017/CBO9780511542008

Dương Trí Dũng, Đoàn Thanh Tâm \& Nguyễn Văn Bé. (2007). Đặc tính thủy sinh vật trong khu đa dạng sinh học ở lâm ngư trường 184, Cà Mau. Tạp chí Khoa học Trưòng Đại học Cần Tho, (7), 85-94.

Flores, M. J. L. \& Zaffaralla, M. T. (2012). Macroinvertebrate composition, diversity and richness in relation to the water quality status of Mananga River, Cebu, Philippines. Philippine Sci. Lett., 5(2), 103-113.

Greene, S.D. (2008). Extending integrated pest management to the golden apple snail: examining a community centre approach in northeast Thailand. Int. J. Pest Manage., 54, 95-102. https://doi.org/10.1080/09670870701621282

Halwart, M. (1994). The golden apple snail Pomacea canaliculata in Asian rice farming systems: 
present impact and future threat. International Journal of Pest Management. 40, 199-206. https://doi.org/10.1080/09670879409371882

Hellawell, J. M. (1986). Biological indicators of freshwater pollution and environmental management. Elsevier, London. https://doi.org/10.1007/978-94-009-4315-5

Hoàng Đình Trung. (2015). Đa dạng thành phần loài động vật đáy (Zoobenthos) ở sông Truồi, huyện Phú Lộc, tỉnh Thừa Thiên Huế. Tạp chi Khoa họ và Công nghệ, (1), 27-33. https://doi.org/10.15625/0866-708X/53/1/3761

Hoàng Đình Trung và Vũ Thị Phương Anh (2017). Đa dạng thành phần loài thân mềm hai mảnh vỏ (Bivalvia) và chân bụng (Gastropoda) ở sông Bồ, tỉnh Thừa Thiên Huế. Tạp chi Khoa hoc-Đại hoc Hué, 126(3C), 13-21. https://doi.org/10.26459/jard.v126i3C.3741

Joshi, R.C., Delacruz, M.S., Martin, E.C., Cabigat, J.C., Bahatan, R.G., Bahatan, A.D., Abayao, E.H., Choy-Awon, J., Chilagan, N.P. \& Cayong, A.B. (2001). Current status of the golden apple snail in the Ifugao rice terraces, Philippines. $J$. Sustain. Agric., 18, 71-90. https://doi.org/10.1300/J064v18n02_07

Köhler, F., Seddon, M., Bogan, A.E., Tu, D.V., SriAroon, P., \& Allen, D. (2012). The status and distribution of freshwater molluscs of the IndoBurma region. In: Allen, D.J. (Compiler), Smith, K.G. (Compiler), Darwall, W.R.T.(Compiler) (Eds.), The Status and Distribution of Freshwater Biodiversity in Indo-Burma. IUCN, Cambridge, UK, Gland, Switzerland, 66-88.

Latha, C., \& Thanga, V. S. G. (2010).

Macroinvertebrate diversity of Veli and Kadinamkulam lakes, South Kerala, India. $J$. Environ. Boil. 31, 543-547.

Madsen, H. \& Hung, H. M. (2014). An overview of freshwater snails in Asia with main focus on Vietnam. Acta Tropica 140, 105-117. https://doi.org/10.1016/j.actatropica.2014.08.005

Nattarin, K., Chanawat, T., Pongrat, D., \& Salinee K. (2014). Species Diversity and Distribution of Freshwater Molluscs after Waterway Dredging in Nongchok Area, Bangkok, Central Thailand. Burapha University International Conference. Burapha University, Thailand.

Nguyễn Thị Kim Liên. (2017). Nghiên cứu phuoong pháp quan trắc sinh học trong đánh giá chất luợng nước trên tuyến sông Hậu sư dụng động vật không xuơng sống cõ lớn. Luận án Tiến sĩ Thủy sản năm 2017. Khoa Thủy sản, Trường Đại học Cần Thơ.

Nguyễn Thị Kim Liên, Huỳnh Trường Giang \& Vũ Ngọc Út. (2014). Thành phần động vật đáy (Zoobenthos) trên sông Hậu. Tạp chí Khoa học Truòng Đại hoc Cần Tho; 2, 239-247.

Pitta, P., Karakassis, I., Tsapakis M., \& Zivanovic, S. (1999). Natural vs. mariculture induced variability in nutrients and plankton in the eastern Mediterranean. Hydrobiologia, 391,181-94.

Qadri, H., \& Yousuf, A. R. (2004). Ecology of macrozoobenthos in Nigeen lake. J. Res. Dev., 4, 59-65.

Sangpradub, N., \& Boonsoong, B. (2006). Identification of freshwater invertebrates of the Mekong River and its tributaries. Mekong River Commission, Vientiane, 274 pp.

Shannon, E., \& Weaver W. (1963). The Mathematical theory of communication. The University of Illionis Press, Urbana. 125 p.

Staub, R., Applying, J. W., Hofsteiler, A. M., \& Hass, I. J. (1970). The effects of industrial wastes on Memphis and Shelby County on primary planktonic producers. Bioscince, 20, 905-912. https://doi.org/10.2307/1295583

Strong, E. E., Gargominy, O., Ponder, W. F., \& Bouchet, P. (2008). Global diversity of gastropods (Gastropoda; Mollusca) in freshwater. Hydrobiologia, 595, 149-166. https://doi.org/10.1007/s10750-007-9012-6

Strzelec, M. \& Królczyk, A. (2004). Factors affecting snail (Gastropoda) community structure in the upper course of the Warta River (Poland). Biologia 59, 159-163.

Temporetti, P. F., Alonso, M. F., Baffico, G., Diaz, D. D., Lopez, W., \& Pedrozo, F. L. (2001). Trophic state of fish community and intensive fish production of salmonids in Alicura Reservoir (Patagonia, Argentina). Lakes Reserv. Res. Manage. 6, 259-267. https://doi.org/10.1046/j.1440-1770.2001.00142.x

Voshell, J. R. (2002). A Guide to Common Freshwater Invertebrates of North America. McDonald \& Woodward Publication.

Yunfang, H. M. S. (1995). Atlas of freshwater biota in China. China Ocean Press. 